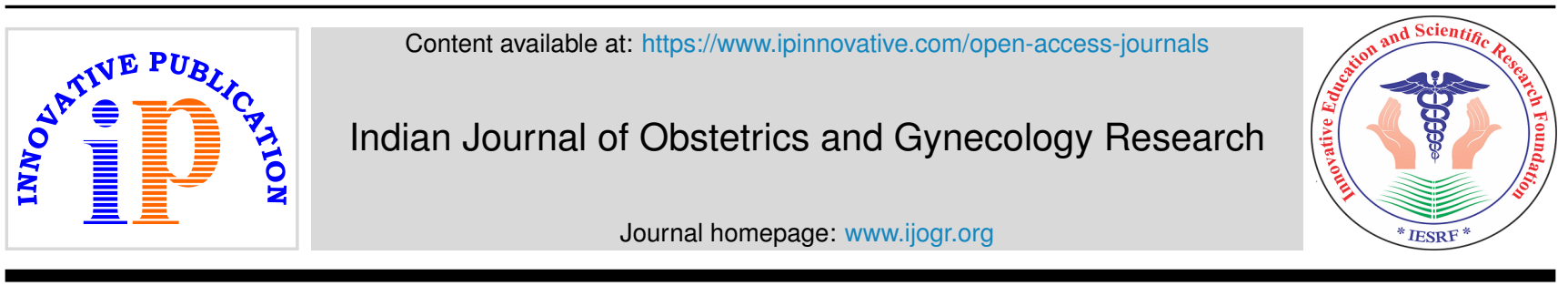

Original Research Article

\title{
A survey of women's birth experiences using the Birth Satisfaction Scale-Revised Indicator (BSS-RI)
}

\author{
Madhumithaa $\mathbf{N}^{1, *}$, N Hephzibah Kirubamani ${ }^{1}$ \\ ${ }^{1}$ Dept. of Obstetrics and Gynecology, Saveetha Medical College and Hospital, Kuthambakkam, Tamil Nadu, India
}

\section{A R T I C L E I N F O}

\section{Article history:}

Received 11-11-2020

Accepted 10-01-2021

Available online 13-03-2021

\section{Keywords:}

Assessment

Birth experience

Birth satisfaction scale

Caesarean delivery

Multiparas

Primiparas

Vaginal delivery

\begin{abstract}
A B S T R A C T
Background and Aims: Birth satisfaction is the key indicator for maternal and perinatal services. Analysis of birth experience is important to improve maternity care. The objective of this article is to assess the birth experience of the women delivering at Saveetha Medical College and Hospital and to compare the satisfaction scores in different modes of delivery and the satisfaction scores amongst women based on their parity.

Materials and Methods: Prospective cross-sectional observational study was conducted after ethical clearance and informed consent, among 100 women going through delivery at Saveetha Medical College, Obstetrics and Gynaecology department. The women were assessed by interview method with the Birth Satisfaction Scale-Revised Indicator and made to score from 0-2. The demographic details of the patient and the type of delivery along with their parity were also included. The results were analysed statistically based on which the care given during intrapartum period can be improved.

Results: Amongst the 100 women who participated in the study, 31 were primiparas and $57 \%$ of the women underwent normal vaginal delivery. The average score in women undergoing normal delivery was 5.15 , with Caesarean section having an average score of 4.62. Multiparous women had an average score of 5.24 compared to primiparous women, who had an average score of 4.22 .

Interpretation and Conclusion: The satisfaction scores of women who underwent normal vaginal delivery was better than those who underwent Caesarean sections. Also, primiparas experienced more distress during labour compared to multiparas.
\end{abstract}

(C) This is an open access article distributed under the terms of the Creative Commons Attribution License (https://creativecommons.org/licenses/by/4.0/) which permits unrestricted use, distribution, and reproduction in any medium, provided the original author and source are credited.

\section{Introduction}

The perinatal well-being of women belonging to the childbearing age group is of paramount importance to all institutions that provide maternity services throughout the country. ${ }^{1}$ The birth satisfaction during this period is of key importance in assessing the care provided and making suitable improvements. The experiences a woman undergoes during childbirth can influence her future childbearing options. The Birth Satisfaction ScaleRevised Indicator (BSS-RI) is a questionnaire that targets to supervise the experience of a childbearing woman during delivery. ${ }^{2}$ The BSS-RI is a six-item scale which is used

\footnotetext{
* Corresponding author.

E-mail address: madhumithaa98@gmail.com (Madhumithaa N).
}

to assess the birth satisfaction of the patients. The women assessed are considered as consumers of maternity care and their experiences are noted to make further improvements in service provision. ${ }^{3}$ Over the years, women's maternity experiences have changed with advancing medical care and hence it is of vital importance to record their views and opinions. Since women consult clinicians most frequently because of childbirth, evaluation of the women's level of satisfaction from intra-, and postpartum health care services provided by the health care setups is very important in increasing the quality of health care. Therefore, the experiences of women during the intrapartum period has gained increasing importance. ${ }^{4-6}$

Experiences related to childbirth directly interfere with the health and well-being of the mother and her new-born, as 
well as with the choice of a future delivery. Dissatisfaction with normal labour calls for an increase in the preference for Caesarean birth in future pregnancies and may cause impact on reproduction. ${ }^{7}$ The concept of satisfaction is complex and hence the patient's satisfaction relies on the degree of quality provided by a health service. Hence, satisfaction with birth expresses the user's assessment of the care received. Also, it is necessary to know more about the satisfaction levels experienced with different modes of delivery (normal delivery and Caesarean section) as this will help in improving the hospital environment according to the women's needs and will also help in improving the women's choice of future delivery. The BSS-RI will provide us with information about improvements in the hospital setup that can be made in order to facilitate a better childbearing experience for the mothers in the future. The varying satisfaction scores with respect to the women's parity will also aid the doctors in introducing psychological counselling for primiparous women about what they need to know and expect, in order to reduce their stress regarding the outcomes of the pregnancy.

\section{Material and Methods}

A prospective cross-sectional study was conducted at the Obstetrics and Gynecology department of Saveetha Medical College and Hospital. After obtaining ethical clearance and informed consent, one hundred women who delivered over a period of three months were included in the study.

\subsection{Description of tool}

The six item Birth Satisfaction Scale-Revised Indicator (Table 1) was used to assess women after delivery. The survey was done by interview method within 10 days after the women delivered in the post-natal ward. The instrument was modified to a simplified 3-point scoring system with higher scores representing greater birth satisfaction (range 0-2). The items in the BSS-RI are further split into 'a-items' and 'b-items' with a separate scoring system for each ('a' items- "agree" $=2$, "agree to some degree" $=1$, "disagree" $=0$; 'b' items- "agree" $=0$, "agree to some degree" $=1$, "disagree" $=2$ ). The BSS-RI is further divided into three domains i.e., quality of care provision, women's self-assessed attributes and stress experienced during labour. The scores of women undergoing different types of delivery (normal vaginal or Caesarean delivery) along with their parities (primipara or multipara) were compared and studied.

\subsection{Inclusion criteria}

All willing mothers undergoing delivery at Saveetha Medical College and Hospital.

\subsection{Exclusion criteria}

1. Women experiencing a perinatal loss.

2. Young mothers less than 18 years of age.

3. Other methods of delivery using forceps or vacuum.

\subsection{Statistical analysis}

For this study, data from 100 women was taken and their BSS-RI scores were analysed. The graphs used in this study were done with MS Excel and the frequency tables were also constructed. The exploratory statistics are given for each item set along with the standard deviation scores.

\section{Results}

A total of 100 women completed the 6-item BSS-RI (Table 1). Out of the 100 women, $57 \%$ underwent normal vaginal delivery while $43 \%$ underwent Caesarean section. Thirty-one participants were primiparas, while the rest were multiparas. The average age of the patients was 25.6 years. The general scores of birth satisfaction were positive, supporting that the women were overall satisfied with the birth experience provided by the institution.

\subsection{Results based on the mode of delivery}

The average satisfaction score in women undergoing normal vaginal delivery was 5.15 , whereas the average satisfaction score in women undergoing Caesarean section was 4.62; indicating that Caesarean section had a lower amount of satisfaction (Figure 1). Satisfaction was also higher in women who delivered in the labour ward than those who delivered in operation theatre.

\subsection{Results based on parity}

The satisfaction scores were also higher in multiparous women with an average score of 5.24 than primiparous women, who had an average score of 4.22(Figure 2).

\subsection{Age group variations}

It can be observed from that most of the women participating in the study belong to an age group of 21 24 with a count of nearly 31 . The least number of women are between the age of 33-36, with less than 5 people. This graph also clearly tells that all the women under the study are within the normal range of childbearing capabilities.

\subsection{Mean and standard deviation}

Table 2 indicates the mean BSS-RI scores with the standard deviation of the scores in parentheses. It can be seen that normal delivery had fetched a higher satisfaction than Caesarean section (C-Section). It can also be seen that BSSRI with"a-items" scoring has a higher mean value, thereby a better score than the "b-items". 
Table 1: Birth Satisfaction Scale-Revised Indicator (BSS-RI)

\begin{tabular}{lll}
\hline BSS-RI item & BSS-RI item content & Domain \\
BSS-RI 1 & I was not distressed at all during labour (a) & Stress \\
BSS-RI 2 & I felt very anxious during labour and birth (b) & Attributes \\
BSS-RI 3 & I felt well supported by staff during my labour and birth (a) & Quality \\
BSS-RI 4 & I found giving birth to be a distressing experience (a) & Stress \\
BSS-RI 5 & I felt out of control during my birth experience (b) & Attributes \\
BSS-RI 6 & The staff communicated well with me during labour (b) & Quality
\end{tabular}

Item scoring- 'a' items- "agree" =2, "agree to some degree" =1, "disagree" = 0 ;

'b' items- "agree" $=0$, "agree to some degree" $=1$, "disagree" $=2$

Table 2: Mean BSS-RI scores for different attributes with standard deviation included in parentheses

\begin{tabular}{lcccc}
\hline Variable & $\begin{array}{c}\text { Normal delivery } \\
(\mathbf{n}=\mathbf{5 7})\end{array}$ & $\begin{array}{c}\text { Caeserean section } \\
(\mathbf{n}=\mathbf{4 3})\end{array}$ & Primiparas $(\mathbf{n}=\mathbf{3 1})$ & Multiparas $(\mathbf{n}=\mathbf{6 9})$ \\
BSS-RI (Total) & $5.15(1.12)$ & $4.62(1.00)$ & $4.22(1.12)$ & $5.24(1.12)$ \\
BSS-RI (a) & $3.03(0.70)$ & $3.65(0.52)$ & $3.38(0.76)$ & $3.26(0.67)$ \\
BSS-RI (b) & $2.12(1.08)$ & $0.97(0.80)$ & $0.83(0.82)$ & $1.98(1.06)$ \\
\hline
\end{tabular}

\subsection{Frequency table}

In Table 3, the characteristics are grouped into three divisions (birthing environment, type of childbirth and educational status) and the frequency based on the parity is mentioned.

\section{Average scores in normal and caeserean deliveries}



Fig. 1: Comparison of scores between normal and Caesarean delivery

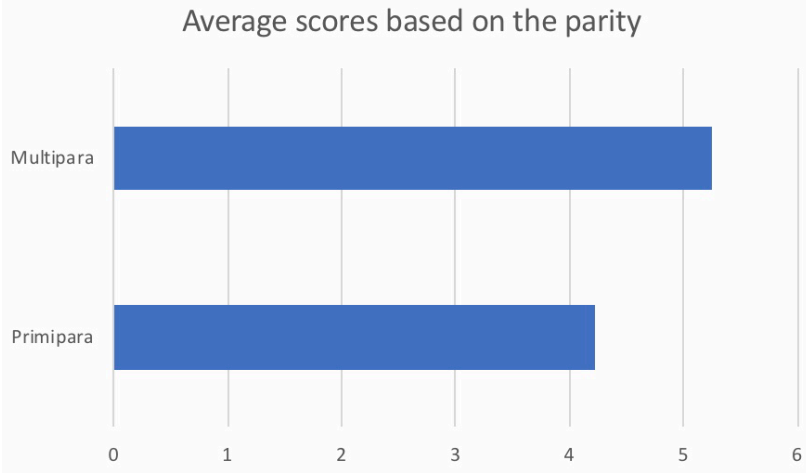

Fig. 2: Comparison of scores between primiparas and multiparas

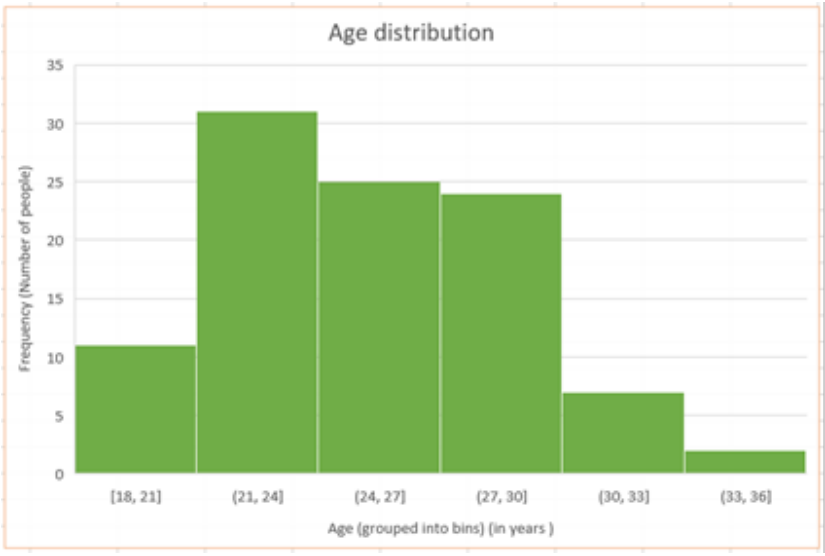

Fig. 3: Distribution of participants - age wise

\section{Discussion}

The overall levels of 'birth satisfaction' were generally high. The first finding in the study was that, women who received Caesarean sections were found to have lesser satisfaction scores compared to the ones who underwent normal vaginal delivery. The literature by Jacoby A also supports that operative interference is often associated with reduced birth satisfaction. ${ }^{8}$ Out of the total 100 patients, $43 \%$ of the patients underwent Caesarean sections. It is evident that women undergoing operative procedures have more anxiety regarding the outcome and future complications that may occur after the procedure. Also, most of the women are not accustomed to the environment in the operation theatre which might lead to more stress and worry. It is therefore vital to counsel all women who are undergoing surgeries and mention the underlying risks and benefits of the same. With an increasing incidence of Caesarean sections in urban setups, it is necessary to make all attempts to reduce the stress and improve satisfaction scores. 
Table 3: Birth characteristics frequency table based on parity

\section{1) Birthing Environment: \\ i) Operation Theatre}

ii) Labour Ward

\section{2) Type of Child Birth:}

i) Normal Delivery

ii) Caesarean Delivery

3) Educational Status:

i ) Middle School

ii) High School

iii) Undergraduate

iv) Postgraduate

\section{Primiparas (n=31)}

Multiparas (n=69)
The study also revealed that primiparas experienced a poorer score of birth satisfaction compared to multiparas. The probable explanation to this could be an increased tendency for primiparas to develop hypertensive disorders in pregnancy, which results in intrauterine growth retardation in our general population. ${ }^{9}$ Increased anxiety about complications is an important contributor to the reduced satisfaction scores in primiparous women. Experiencing labour for the first time can cause more worry and fear in women, which in turn reduces the satisfaction levels. Also, multiparous are more prepared due to prior experience with delivery.

\section{Conclusion}

Our study shows that the birth satisfaction is less among primiparas compared to multiparas and women who underwent caesarean section compared to normal delivery. The overall average score of the BSS-RI was 4.95. The BSSRI has proved to be a useful tool in measuring the birth experiences of childbearing women.

\section{Source of Funding}

None.

\section{Conflict of Interest}

The authors declare that there is no conflict of interest.

\section{References}

1. Department of Health. Changing childbirth: report of the expert maternity group (Cumberlege report). London: HMSO; 1993.
2. Martin $\mathrm{CH}$, Fleming $\mathrm{V}$. The birth satisfaction scale. Int J Health Care Qual Assurance. 2011;24(2):124-35. 10i:0س08/0952686سणس05086

3. Martin CR, Martin $\mathrm{CH}$, Redshaw M. The Birth Satisfaction Scale-Revised Indicator (BSS-RI). BMC Pregnancy Childbirth. 2017;17(1):277. 10ن-10/186/50884-017-1459-7.

4. Johnson M, Langdon R, Yong L, Stewart H, Kelly P. Comprehensive measurement of maternal satisfaction: The modified Mason Survey. Int J Nurs Pract. 2002;8(3):127-36. doi:10.1046/j.1440 ए72 $200200353 \times$.

5. Main EK, Bloomfield L, Hunt G. Sutter Health First Pregnancy and Delivery Clinical Initiative Committee Development of a large-scale obstetric quality-improvement program that focused on the nulliparous patient at term. Am J Obstet Gynecol. 2004;190:1747-58.

6. Janssen PA, Dennis CL, Reime B. Development and psychometric testing of the care in obstetrics: Measure for testing satisfaction (COMFORTS) scale. Res Nurs Health. 2006;29(1):51-60. तoi:10.1002/nur 2012

7. Peterson WE, Charles C, DiCenso A, Sword W. The Newcastle Satisfaction with Nursing Scales: a valid measure of maternal satisfaction with inpatient postpartum nursing care. $J$ Adv Nurs. 2005;52(6):672-81. do1:10.1111/J.1365-2648.2005.03634.X

8. Jacoby A. Women's preferences for and satisfaction with current procedures in childbirth: findings from a national study. Midwifery. 1987;3:117-24.

9. Kaur J, Kaur K. Obstetric complications: Primiparity versus multiparity. Eur J Exp Biol. 2012;2(5):1462-8.

\section{Author biography}

Madhumithaa N, Student

N Hephzibah Kirubamani, Professor

Cite this article: Madhumithaa N, Kirubamani NH. A survey of women's birth experiences using the Birth Satisfaction Scale-Revised Indicator (BSS-RI). Indian J Obstet Gynecol Res 2021;8(1):35-38. 